\title{
دور الإعلام في تفعيل ثقافة ترشيد الاستهلاك
}

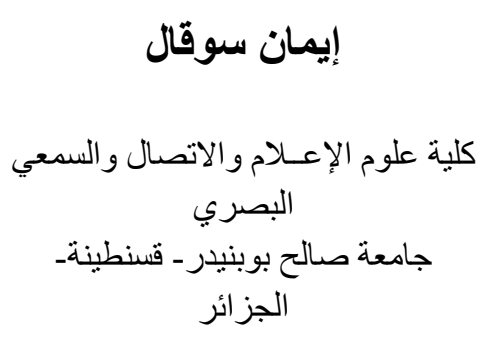

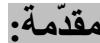

إن تجاوز المفهوم الاقتصادي المحض بدض

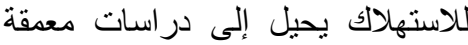

للعملية الاستهلاكية ويوسع من الاهتمام

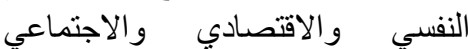

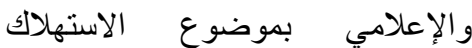

ودراسة الظاهرة في سياقها البنائي

والثقافي. فبانتشار الثقافة الاستهلاكية

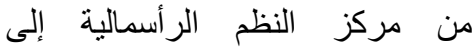

محيطات العالم الثالث التي جعلت

الأفر اد يتدافعون نحو الاستهلاك بغض الت الت التهات

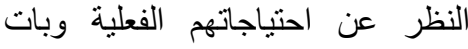

ستههلاك الأشياء يسبق انتاجها، وفي

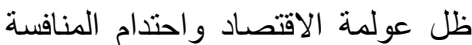

وطغيان ثقافة الاستهرلاك اندمج الإنسان

في هذا المجتمع الجديد إلى درجة أنها

لقب بالإنسان المستهلك.
شملت المظاهر الاستهلاكية كل شيء و أصبحت تسبطر على كل تصرفات

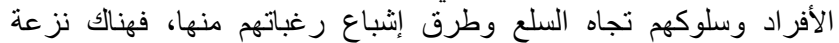

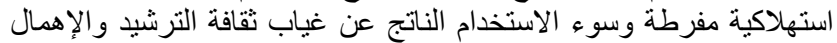
وعدم الاكتراث مما يسهم في هدر الأنية الثروة الطبيعية وأثنار سلبية بيئية

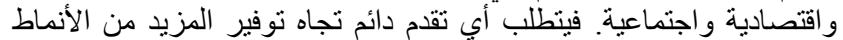

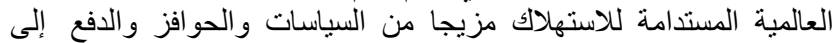

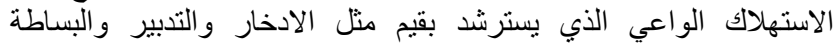

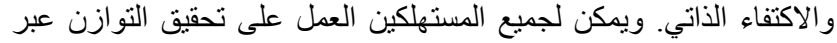

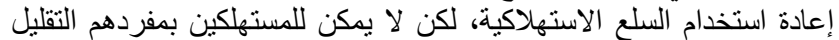

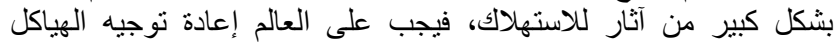

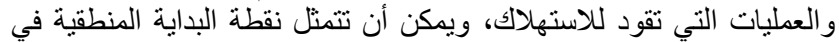

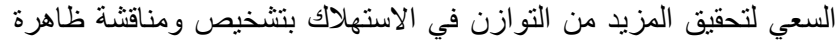

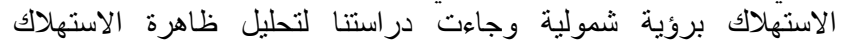
ومنطلبات استهلاك منو ازن مسؤول مرشد لتحفية لتحقيق تنمية مستدامة. الكلمات المفتاحية: الاستهلاك، ثقافة ترشيد الاستهلاك، الإعلام الترشيدي. تُشئ

\section{Abstract:}

The consumption aspects have included everything and became control all the behavior of individuals and their behavior towards goods and ways to satisfy their desires. There is an excessive consumerism and misuse resulting from the absence of a culture of rationalization, neglect and indifference which contributes to waste of natural wealth and negative environmental, economic and social effects. Any sustained progress toward more sustainable global consumption patterns requires a mix of policies, incentives and a conscious consumption guided by values such as savings, management, simplicity and self-sufficiency. All consumers can work to balance through the re-use of consumer goods, but consumers alone can not significantly reduce the effects of consumption. Therefore, the world must reorient structures and processes that lead to consumption, as the logical starting point could be to seek greater balance in consumption by diagnosing and discussing consumption with a holistic vision.

Our study aims to analyze consumption phenomenon and balanced, responsible and rational consumption requirements to achieve sustainable development.

$\underline{\text { Keywords: }}$ : consumption, culture of consumption rationalization, rationalization media.

2017 جامعة الإخوة منتوري قسنطينة، الجزائر (C) 
وكان من اللازم ضبط العلاقة بين المستهلك و التناجر وخصص يوم 15 مارس من كل عام يوما عالمبا

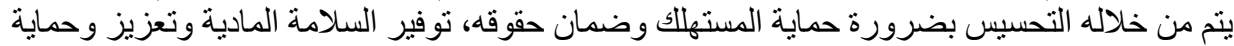

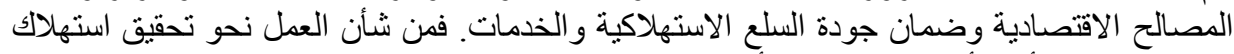

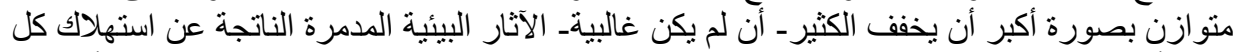

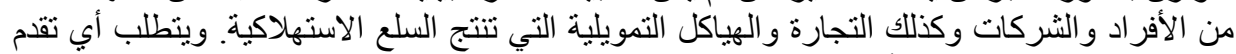

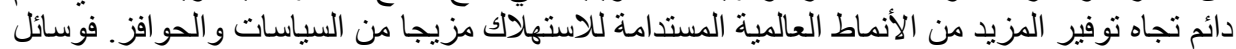

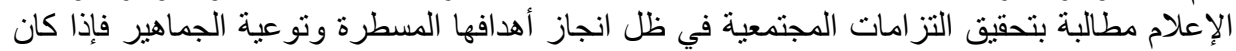

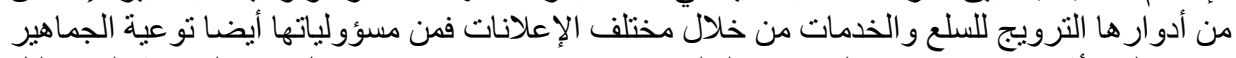

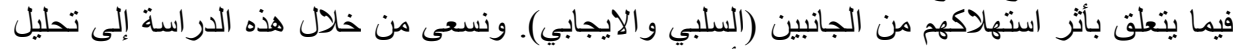

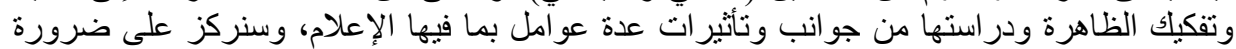
تتخيص الوضع وقراءته في أطره النظرية من خلال إبراز دور دور الإعلام في تفعيل ثقافة نرشيد

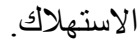

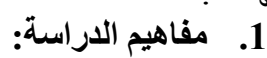

يقول الباحث ولف دينر إبروين Wolf-Dieter Eberwien أن صياغة المفاهيم هي القاعدة

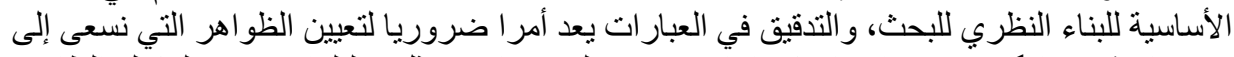

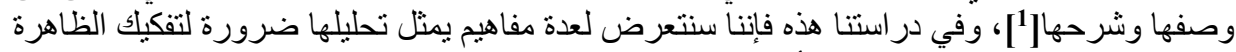
والكثف عن متغير ات الدراسة ومن أبرز ها:

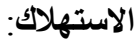

لغة "من هلك هلاكا و هلكا وتهلكة بزيادة الألف و السين و التاء و هلاك بمعنى فنى، ماتـ استهلاكه.

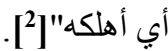

أما اصطلاحا: يعرف بأنه:" استخدام العمل لإشباع حاجة، وهكذا يميزون بين نوعين من

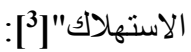

الاستهلاك غير المباثر: الذي ليس له منفعة إلا في صورة المنتجات الجديدة التي يصبح من

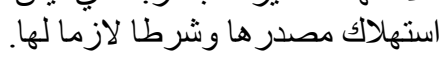

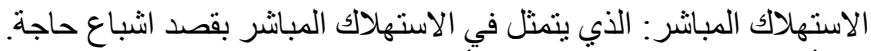

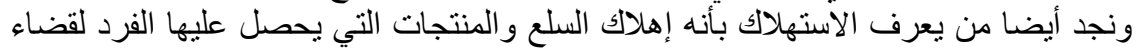

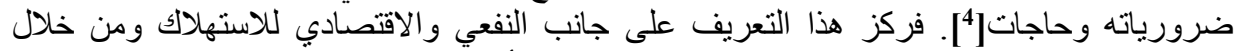

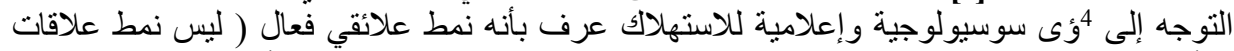

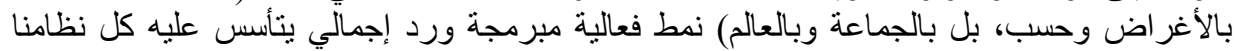

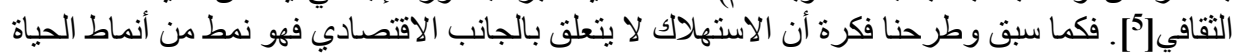

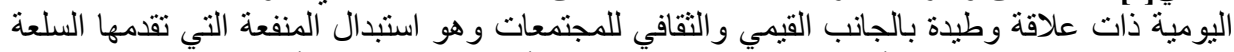

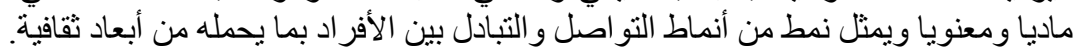

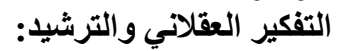

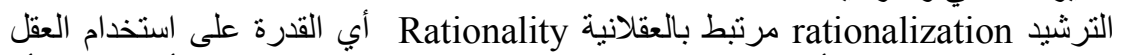
بطرق صحيحة وتوجيه الآراءو والأفعال بحسب المنطق و المعرفة وليس المعتقدات السائدة أو المشاعر أو الو الئل

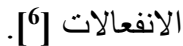

وقد تزامن ظهور المجتمع الحديث في نظر ماكس فيبر مع بروز تغيرات مهمة في أنماط الفعل

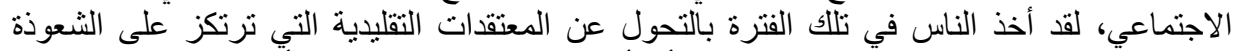

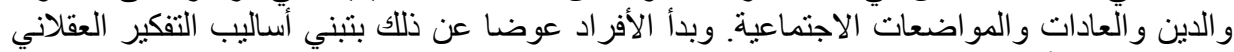

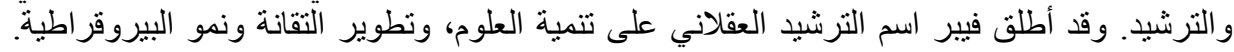

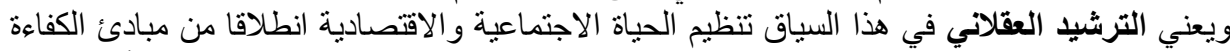

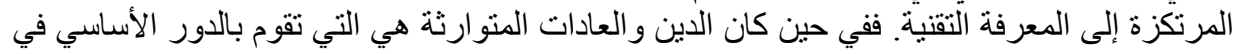


تحديد ما يحمله الناس من قيم واتجاهات في المجتمعات التقليدية، أخذ المجتمع الحديث يتميز بالترشيد

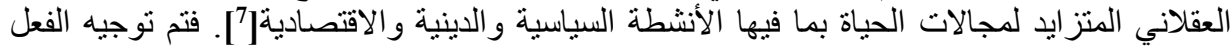

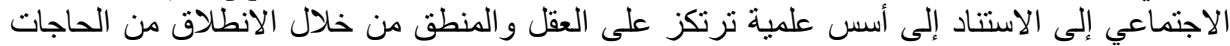

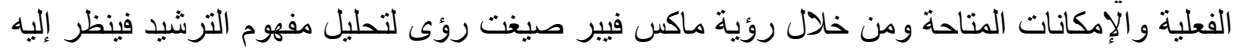

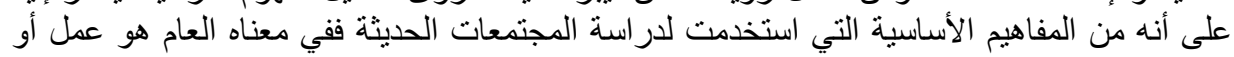

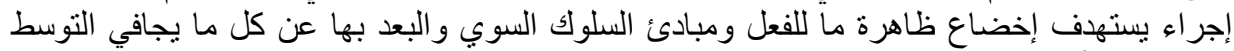

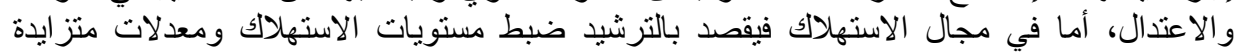

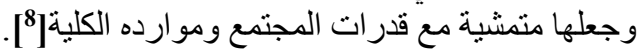

إذا كان المستهلك هو العنصر الذي يسعى إلى الستى الستخدام السلع و الخدمات لإشباع حاجاته أو إنتاج سلع وخدمات جديدة" فالمستهلك الرشيد هو الذي يجعل استهلاكه في دخله الدائم وليس الأليس الدخل الفعلي التي

A rational consumer is who makers his consumption in his permanent income not in functional income) وترشيد الاستهلاك لا يعني تقليل الاستهلاك أو الاستغناء عن الضروريات بل عدم الإسراف في أي شيء يتصنل بالمآكل أو الملبس أو المسكن ومحتوياته.

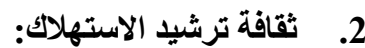

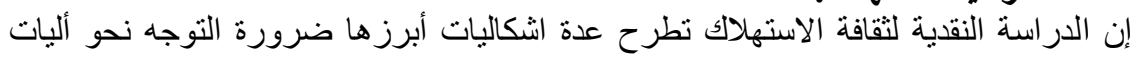

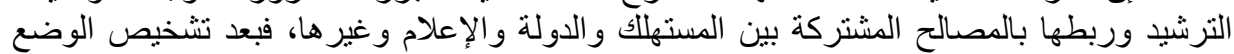

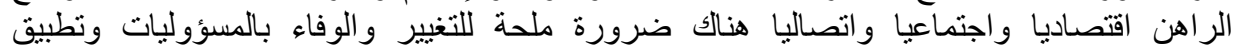

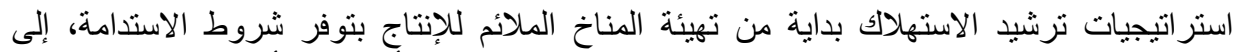

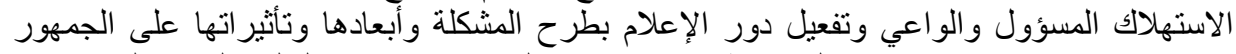

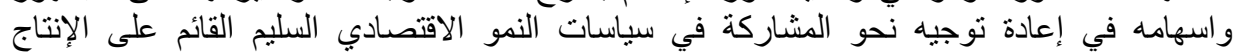

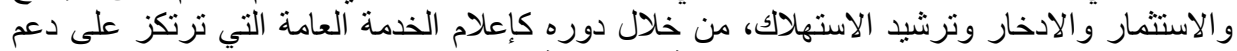

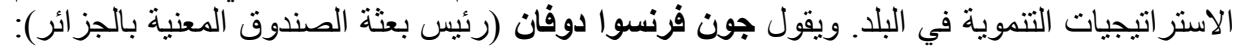

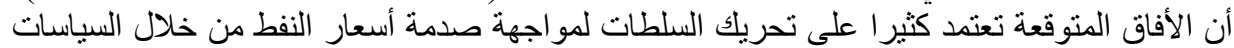

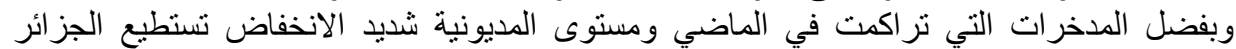

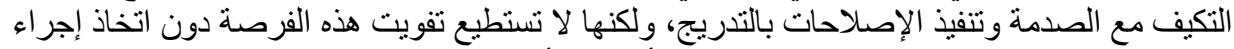

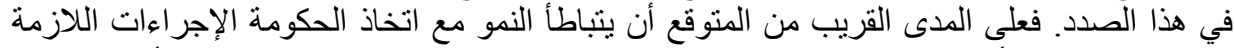

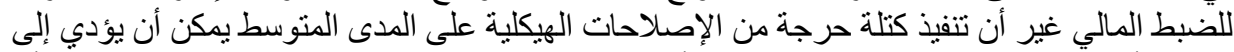

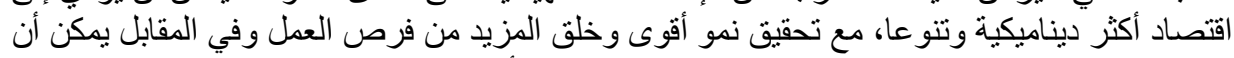

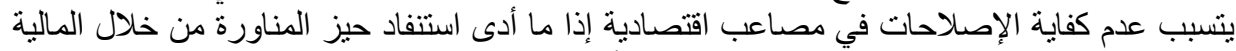

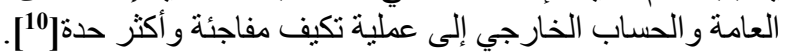
3.

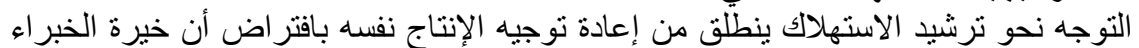

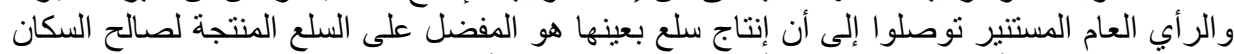

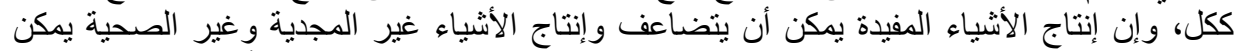

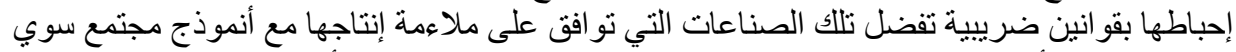

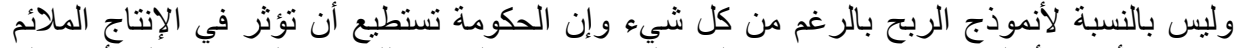

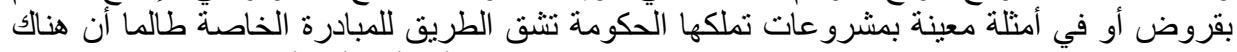

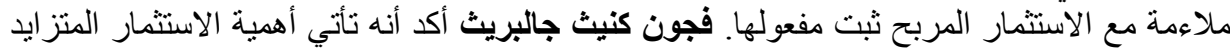


في القطاع العام بالنسبة للاستثمار في القطاع العام مثل النقل العام والإسكان و الددارس والباحات

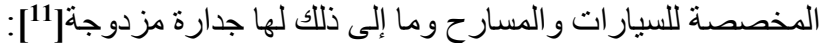

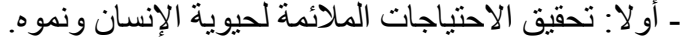

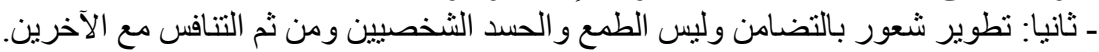

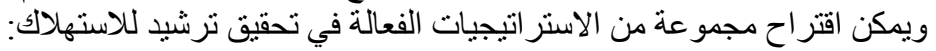

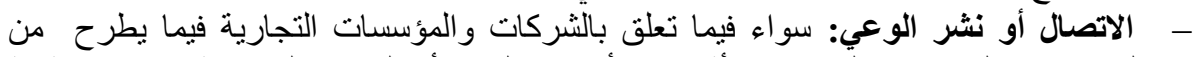

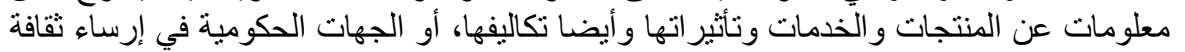

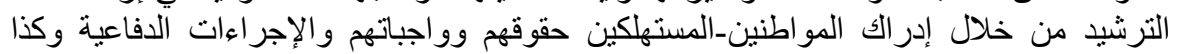

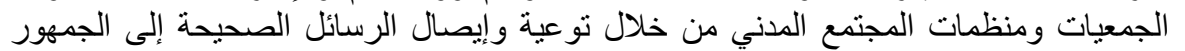

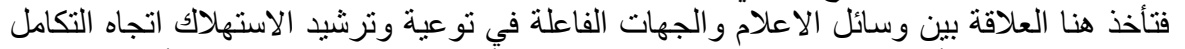

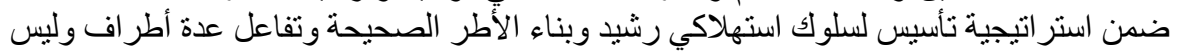

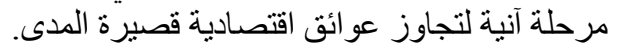

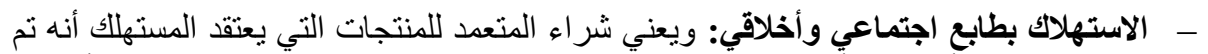

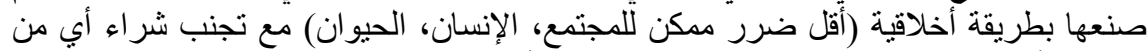

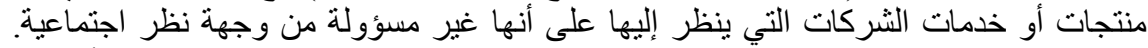

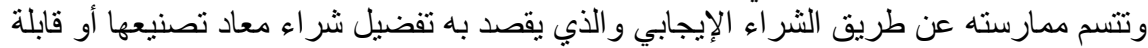

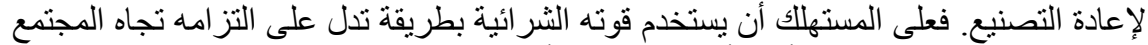

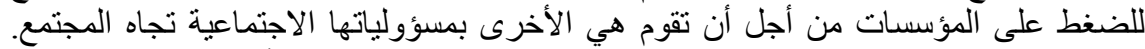

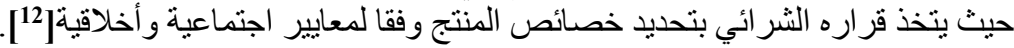

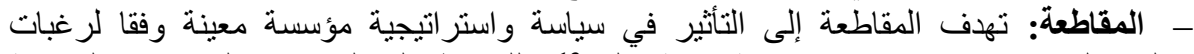

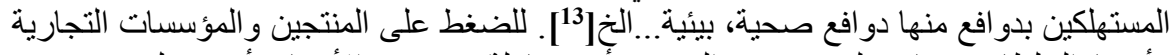

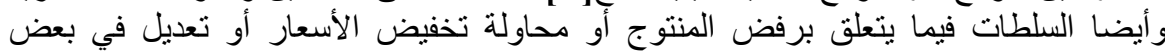
الميزات وقد يتطلب هذا الوضع تسيير وتخطيط تتولى رئاسته منظمات المجتمع المدني لتحقيق مطالب مشرو عة للمو اطنين- المستهلكين.

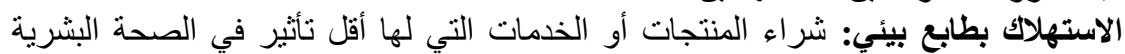

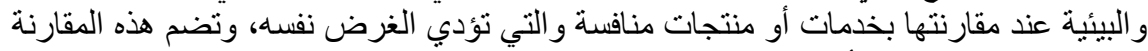

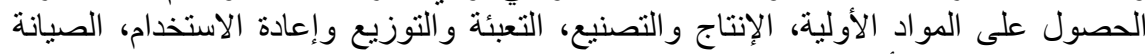

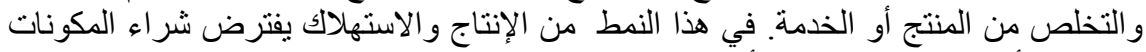

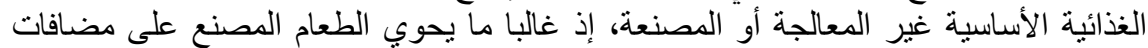

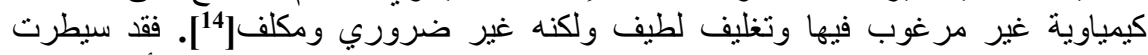

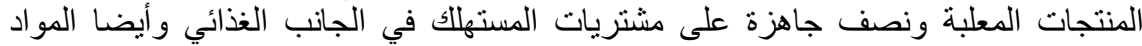

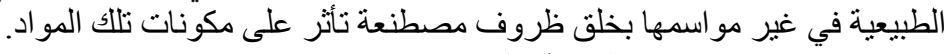

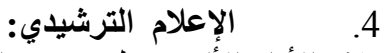

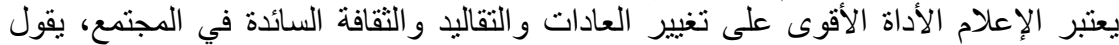

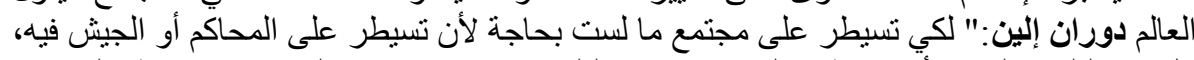

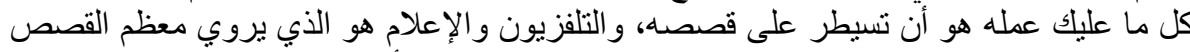

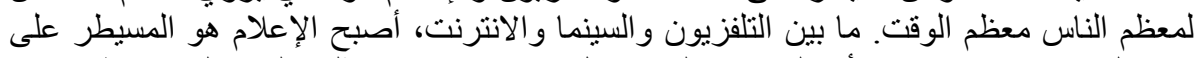

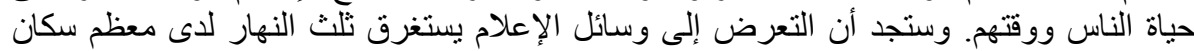

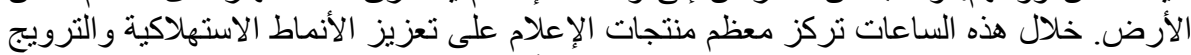

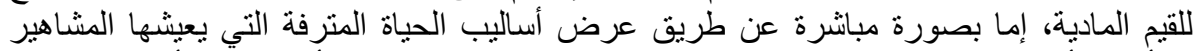

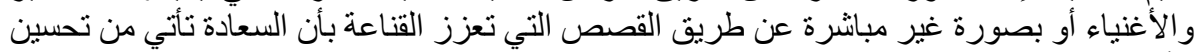

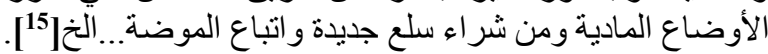




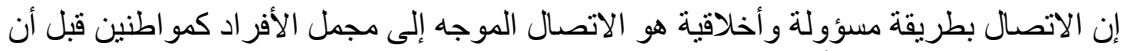

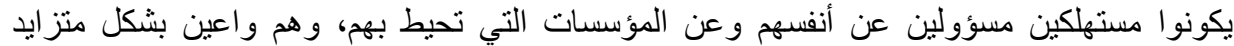

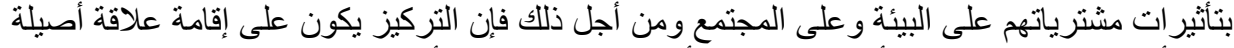

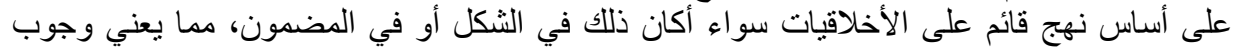

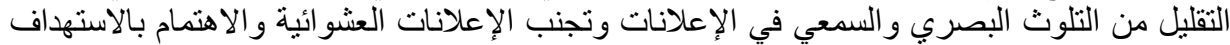

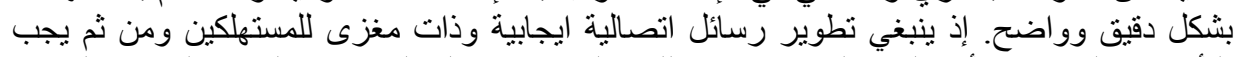

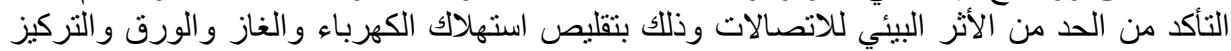

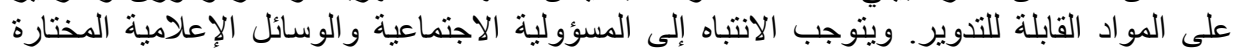

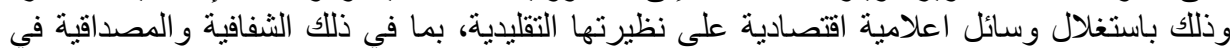

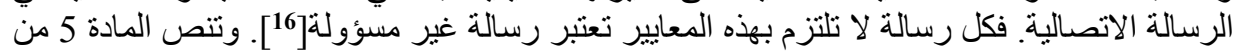

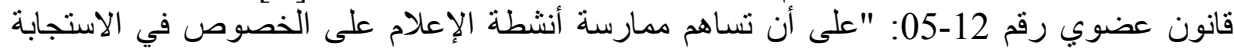

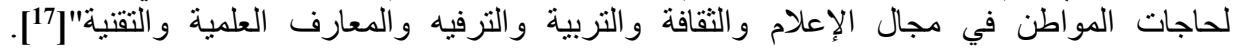

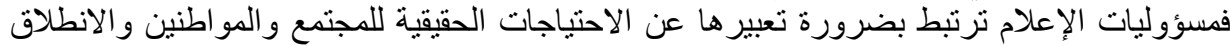

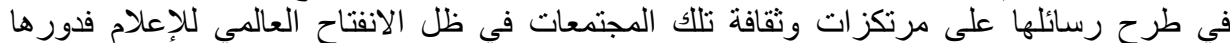

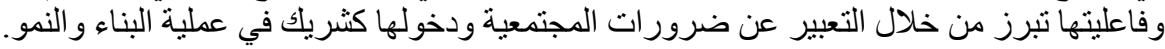

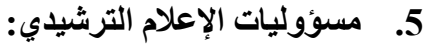

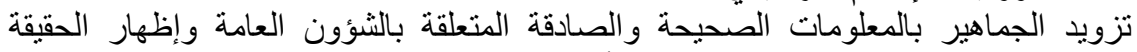

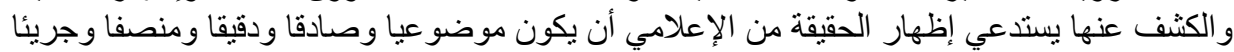

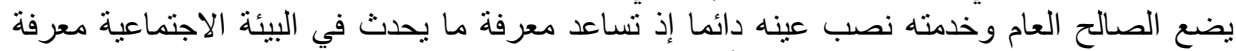

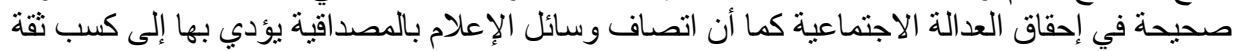

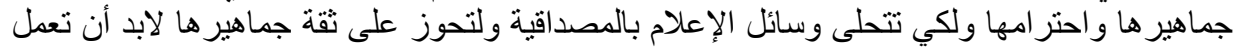

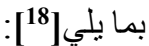

- ـ أن تتأكد من صحة الأنباء والمعلومات التي تقدمها للجماهير وصدق تلك الأنباء و المعلومات

$$
\text { ودقتها. }
$$

- ـ أن تحافظ على الحياد عندما تعالج القضايا الجدلية ويتم ذللك بإظهار وجهات النظر لمختلف

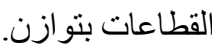

- - أن تختار من الأنباء و القضايا تلاك التي تتعلق بالجمهور وتهمه وتخدم مصالحهـ.

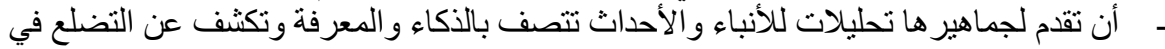

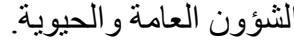

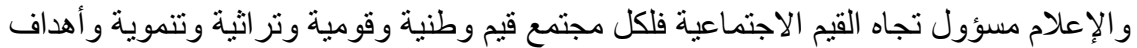

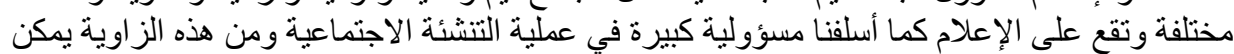

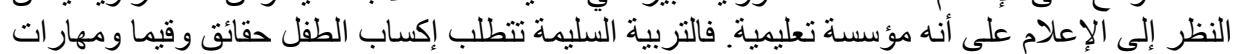

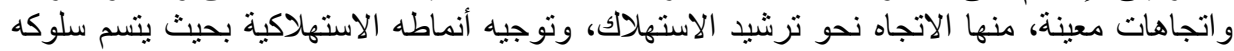

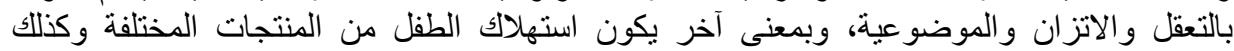

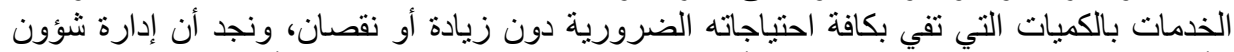

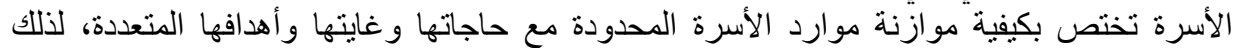

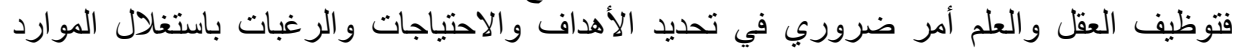

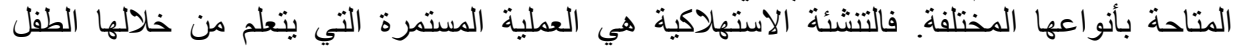

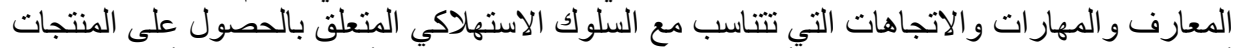

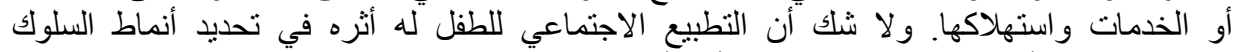

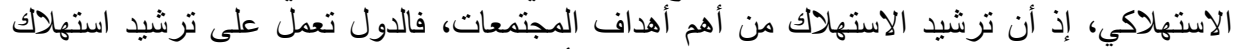

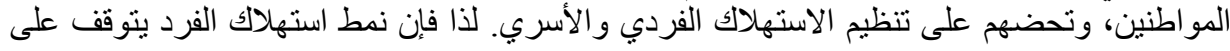


مدى و عيه بأهداف الدولة وسياستها الاقتصادية. كما يتوقف على نوعية المعلومات و العادات التي

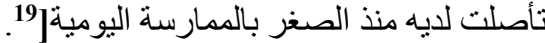

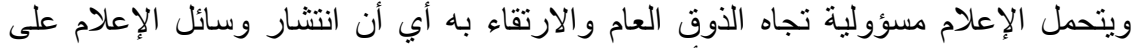

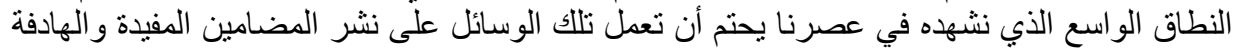

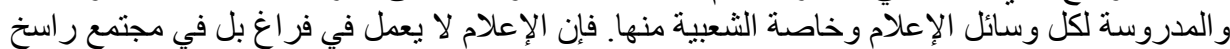

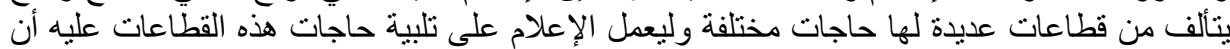

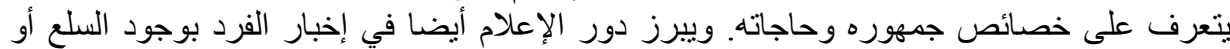

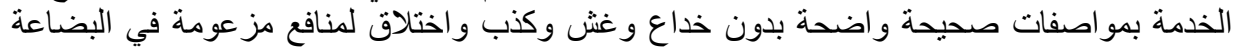

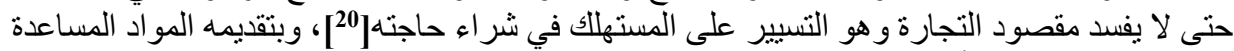

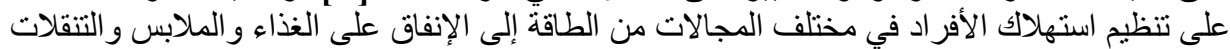

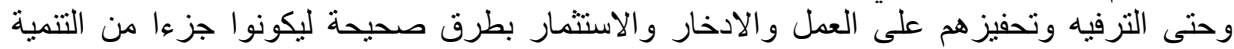
المستدامة في الجز ائر وفي الدول وفئ النامية.

فيرى روبير اسكاربيت أن وسائل الإعلام والتي توصف الأنية بأنها جماهيرية هي الوحيدة القادرة

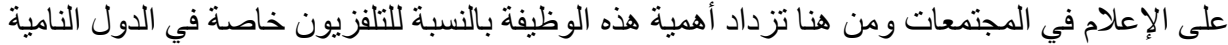

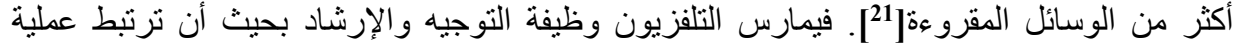

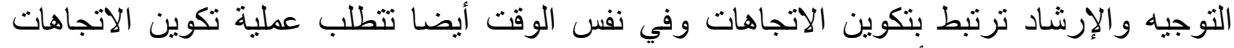

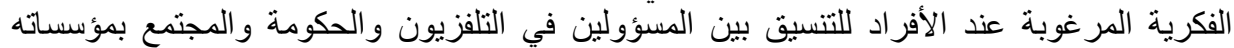

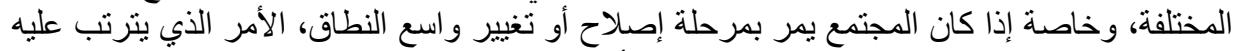

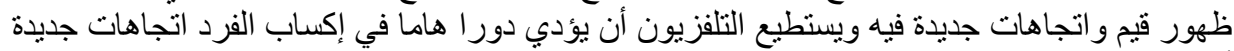

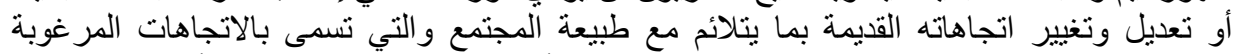

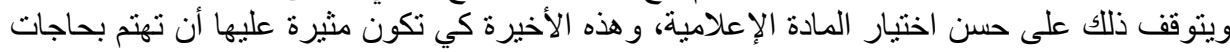

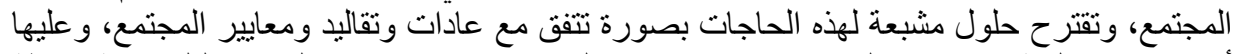

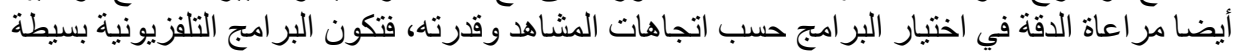

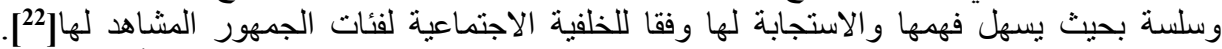

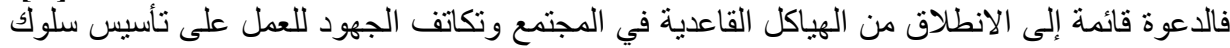

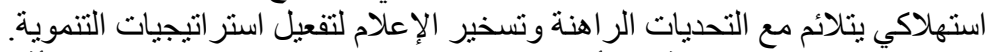

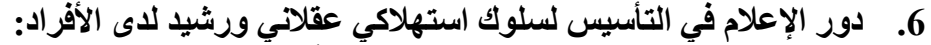

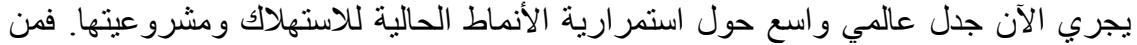

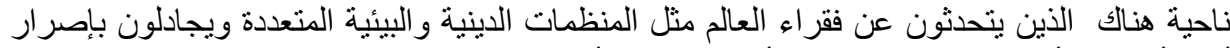

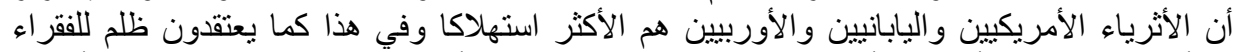

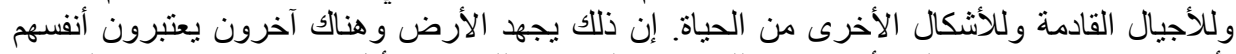

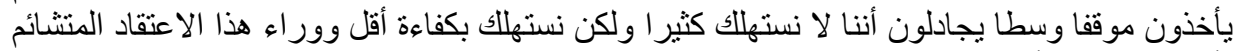

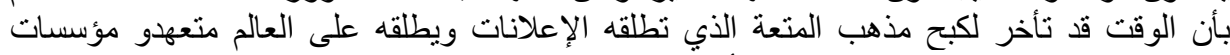

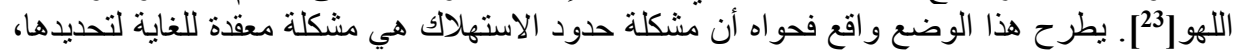

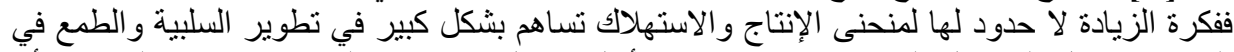

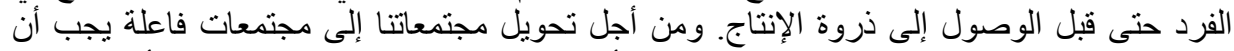

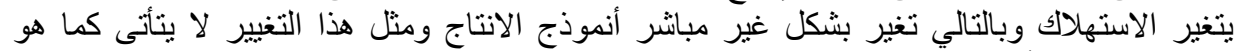

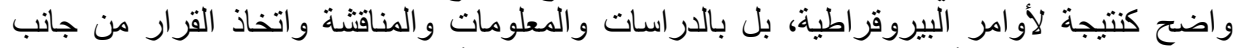

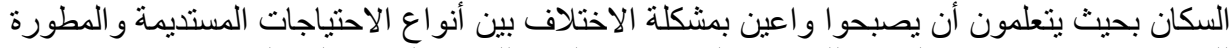

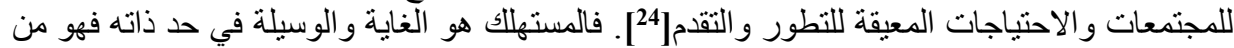

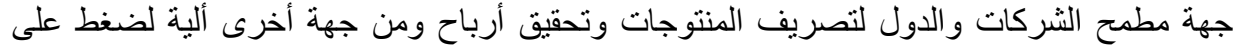


السلطات و الحكومات ودفعها للمديونية و الاستير اد ودخول في صر اعات سببها الحاجة إلى تحقيق الأمن

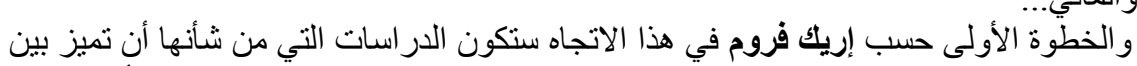

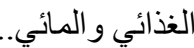

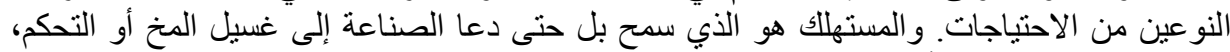

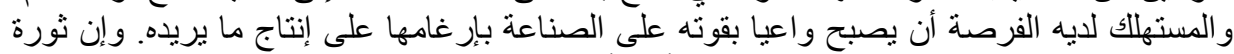

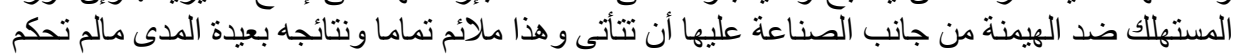

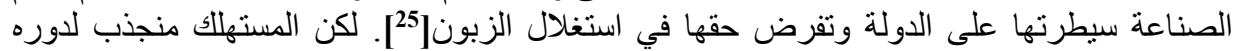

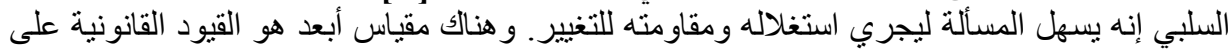

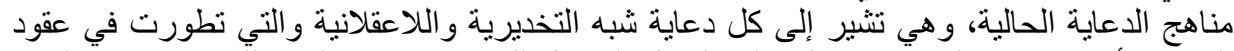

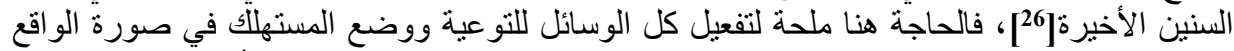

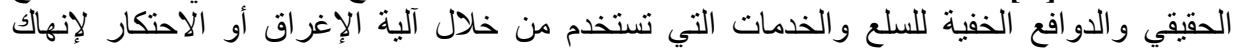

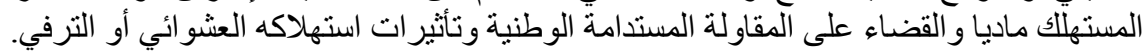

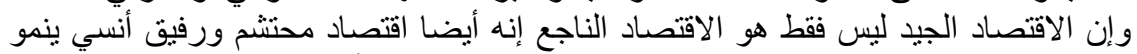

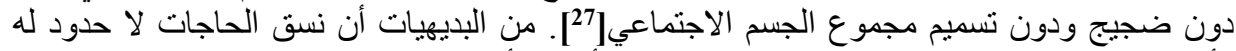

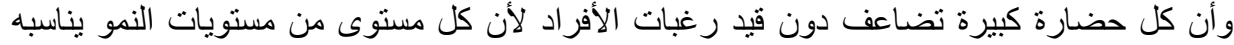

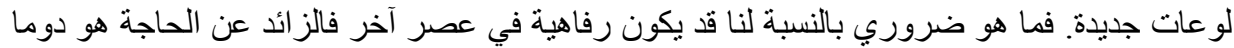

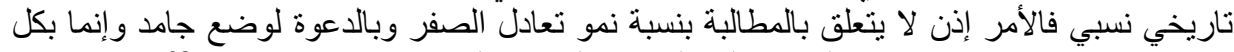

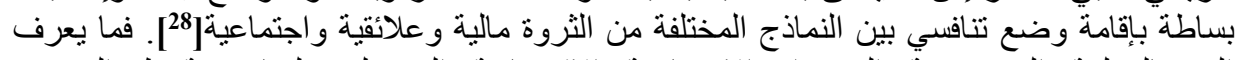

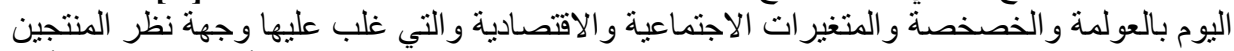

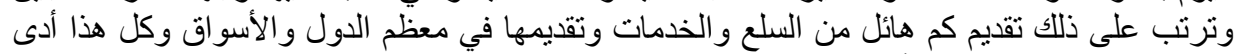

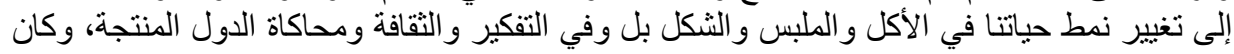

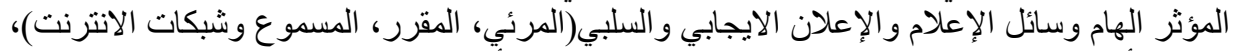

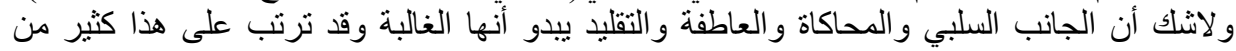

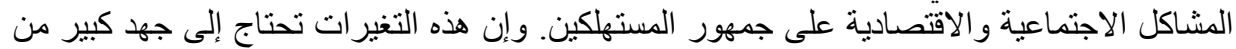

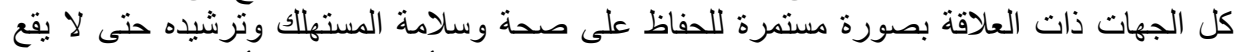

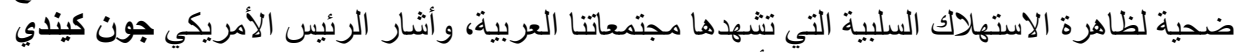

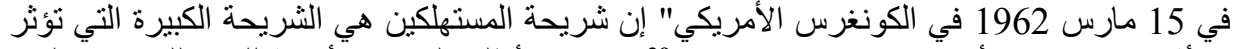

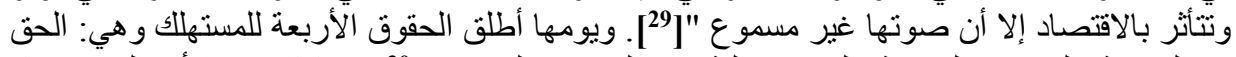

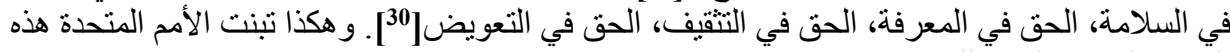
الحقوق لحماية المستهل في وترشيدها.

وتبنت الجمعية العامة للأمم المتحدة بقرارها المرقم

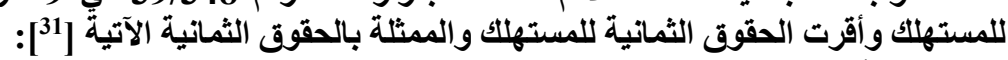

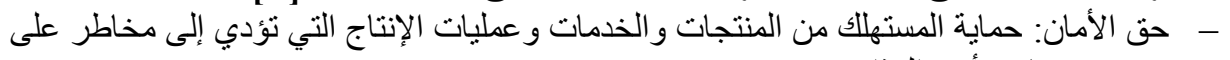

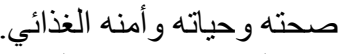
- - حق المعرفة: تزويد المستهلك بالكالكقائق التي تساعد على قيامه بالاختيار السليم، وحمايته من

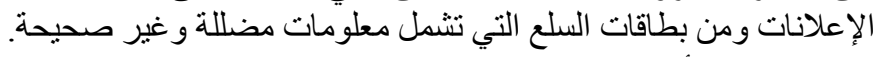

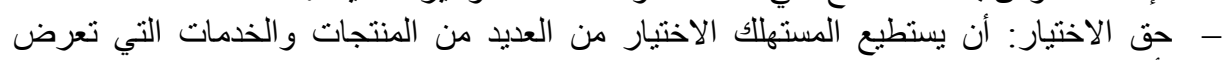

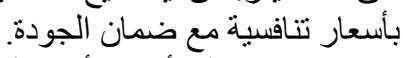
- حق الاستماع إلى أراءه: أن تمثل مصالح المستهلك في إعداد سياسات الدولة وتتفيذها وفي تطوير

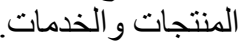
- حق إثباع احتياجاته الأساسية: أن يكون للمستهلاتك حق الحصول على السلع الضرورية الأساسية وكذلك الخدمات كالغذاء و الكساء و المأوى و الرعاية الكانية الصحية و التعليم. 


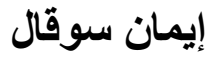

ـ حق التعويض: أن يكون للمستهلك الحق في تسوية عادلة لمطالبة المشروعة، شاملة التعويض عن

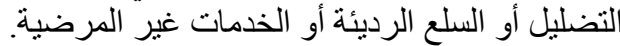

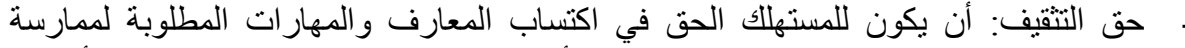

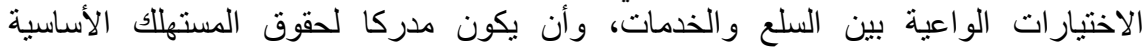
ومسؤوليته وكيفية استخدامها. ـ حق الحياة في بيئة صحية: أن يكون للمستهلئه الحق في أن يعيش ويعمل في بيئة خالية من المخاطر للأجيال الحالية و المستقلية.

لعل من أهم المبادئ التوجيهية لحماية المستهولالك الصادرة عن الجمعية العامة للأمم المتحدة، مبدأ

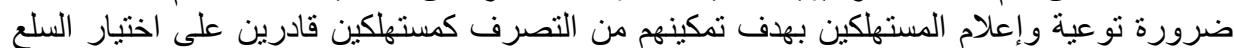

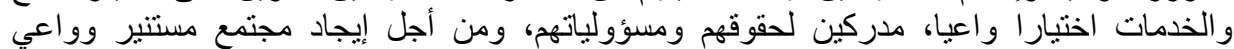

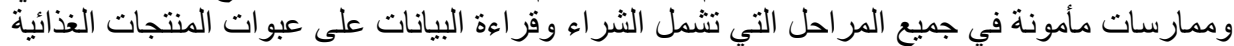

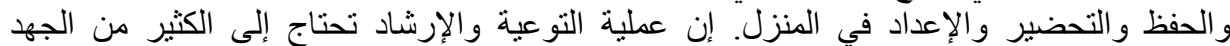

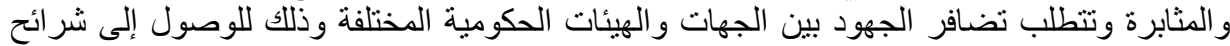

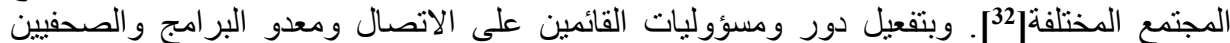

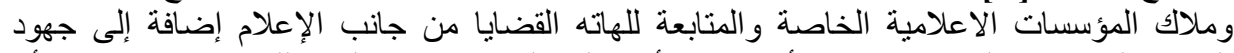

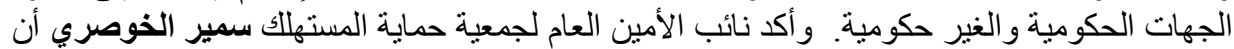

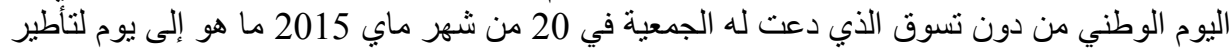

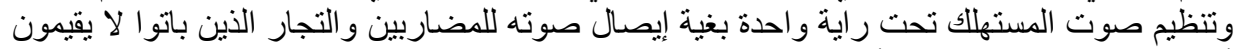

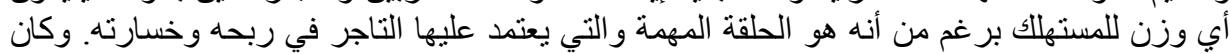

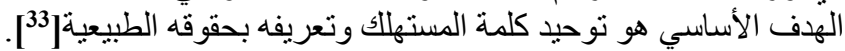

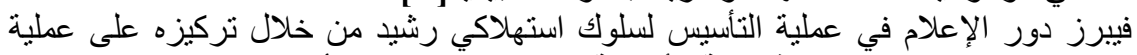

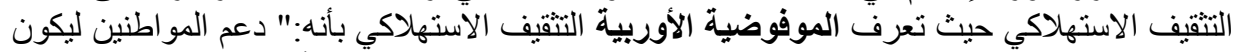

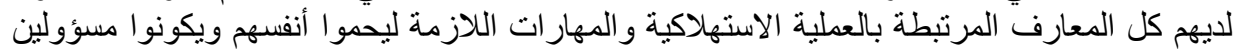

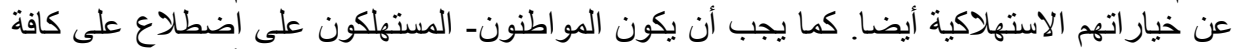

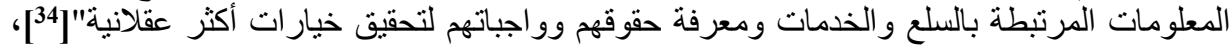

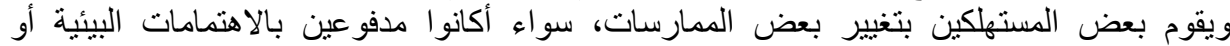

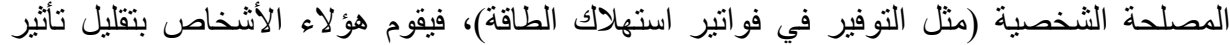

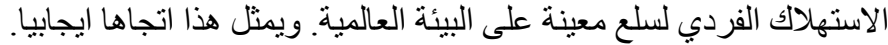

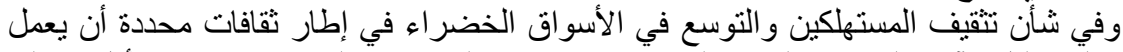

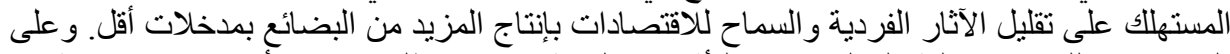

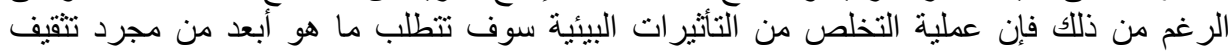

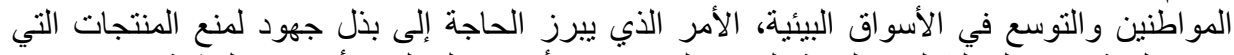

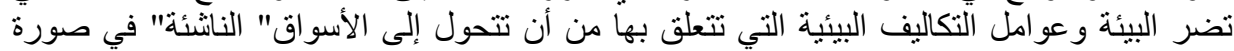

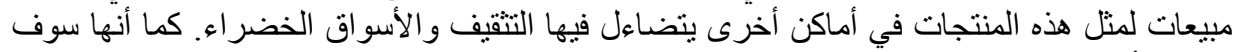

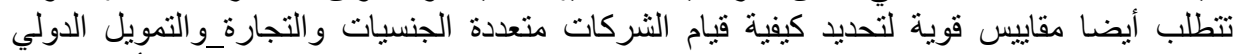

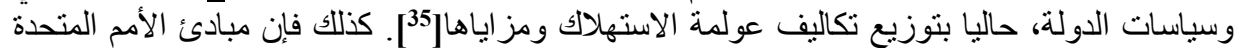

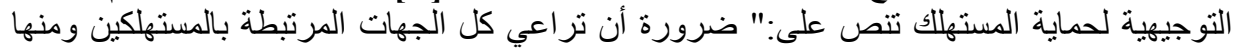

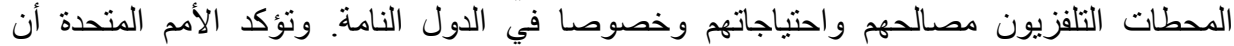

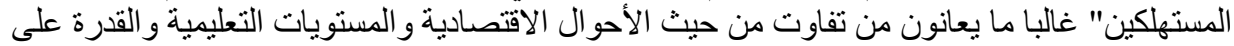

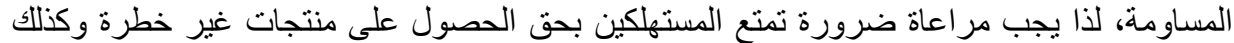

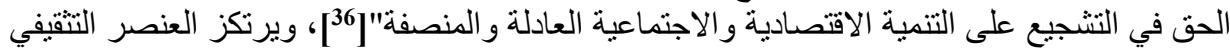


و الإرشادي للمستهلك على رفع و عيه وتبصبره بحقوقه وو اجباته، بما يرشد قر ار اته ويوجه إلى ما يحقق له القدر الأكبر من الحماية وذلك من خلال:

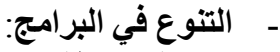

إن متابعة خريطة الإرسال تحيل إلى أن هناك قدر من التشابه يصل إلى حد التطابق في الأفكار

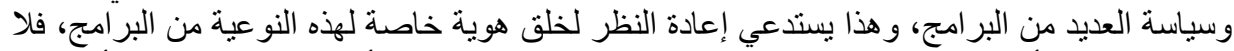

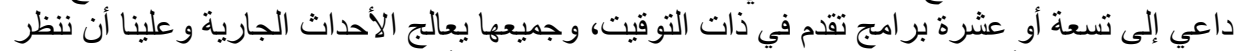

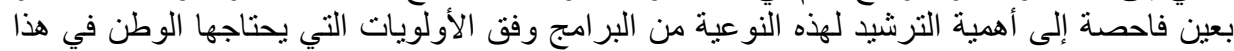

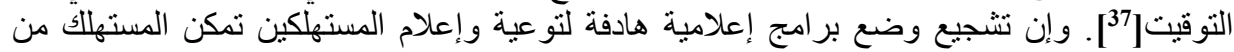

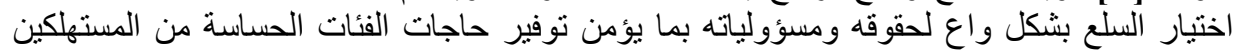

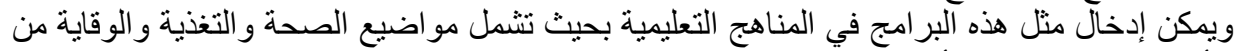

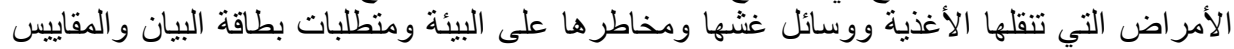

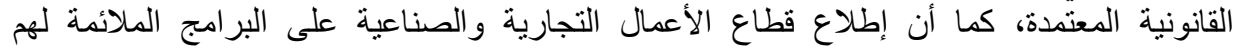

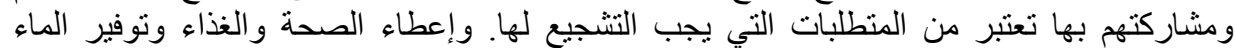

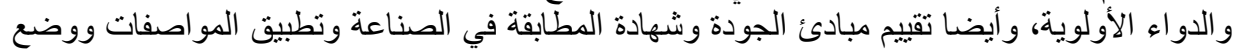

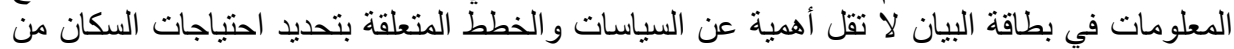

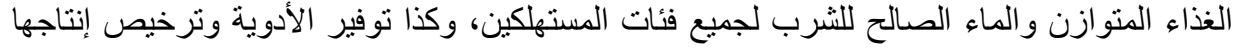
وتوزيعها وتسجيلها بما ينسجم مع الضواه ابط العالمية.

- مشاركة الجمهور في الرسالة الإعلامية:

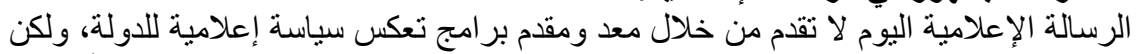

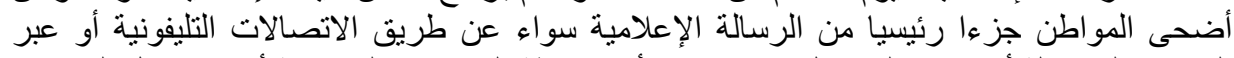

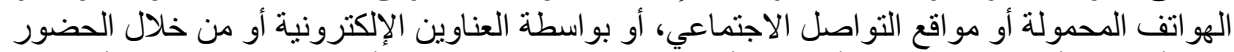

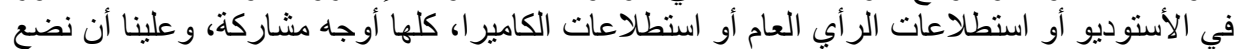

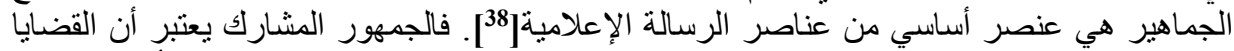
المطروحة في الرسالة الإعلامية تعبير عن احتياجاته ويثكل تفاعله مع تلإلك الرسائل إلز ام أخلاقي لتنبني وتفعيل طرق العقلانية في استهلاكها

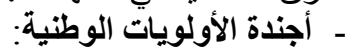

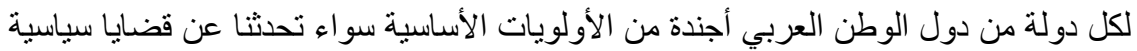

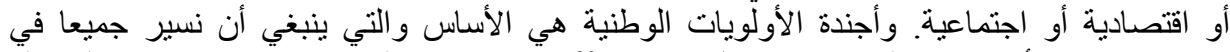

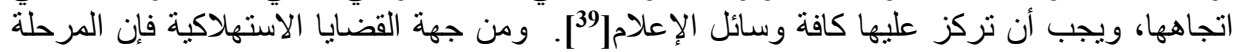

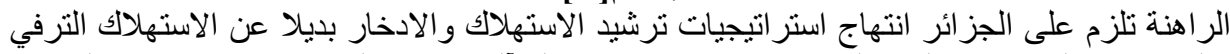

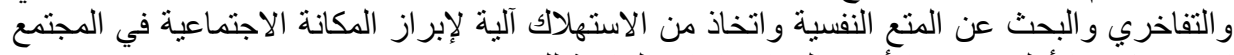

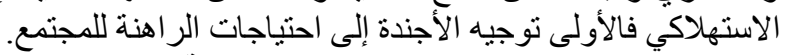

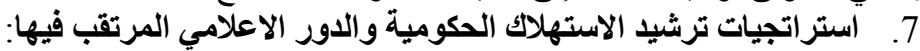

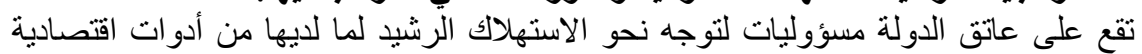

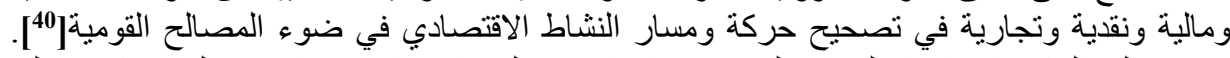

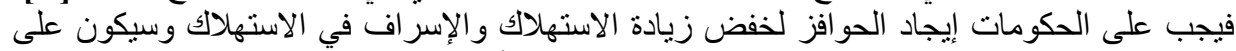

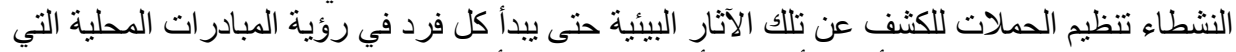

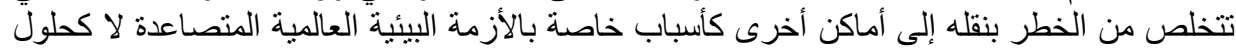

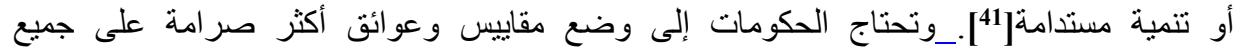

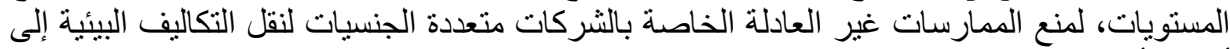
أماكن أخرى. وتسنطيع المنظمات غير الحكومية المساعدة هنا عبر إطلاق حملات لتوضيح هذه 


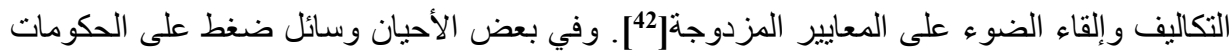

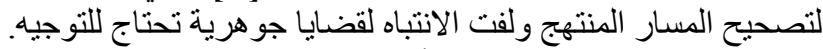

ويرى مصطفى التير أن طبيعة النظام الاجتماعي الذي يشتمل النياه على الجانبين السياسي

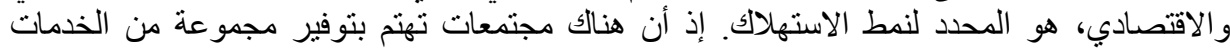

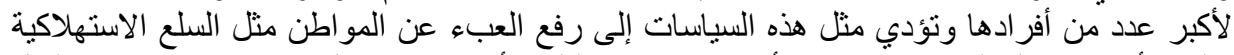

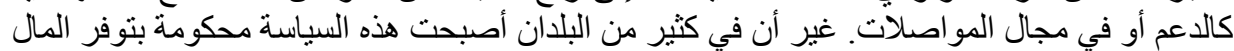

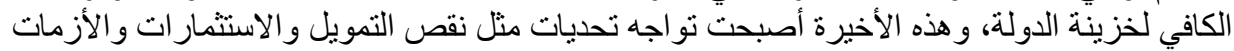

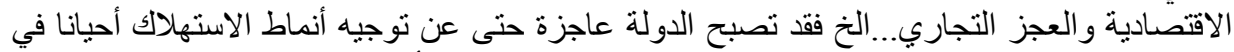

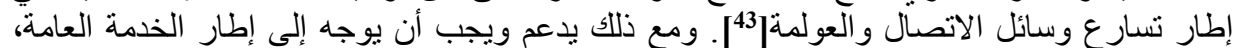

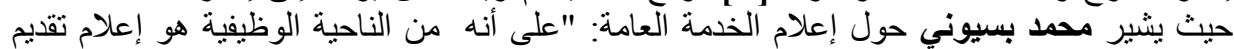

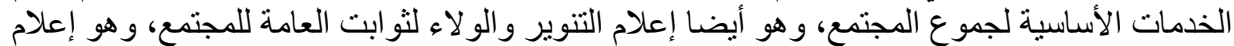

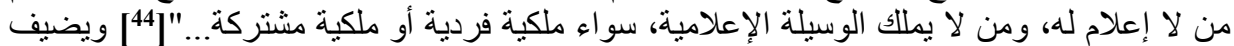

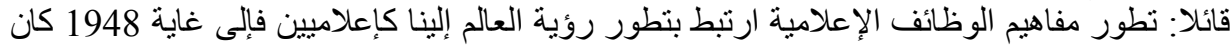

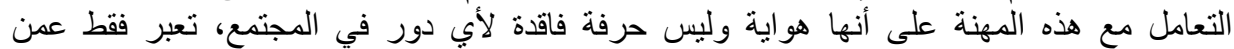

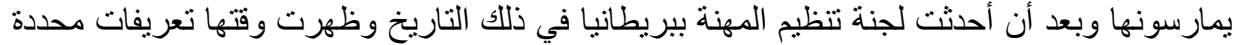

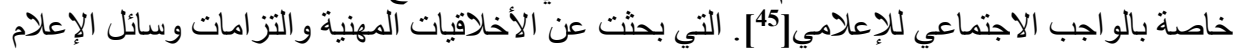

وتثير أليسندرا باراديزي Paradisi Alessandra (المديرة العامة للعلاقات الدولية بهيئة ومسؤولياتها تجاه المجتمع و الفرد.

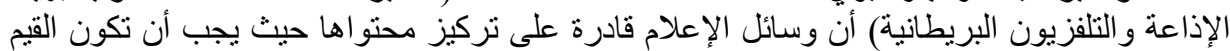

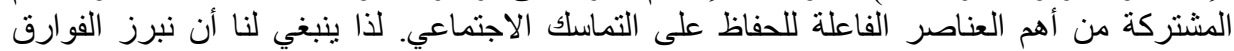

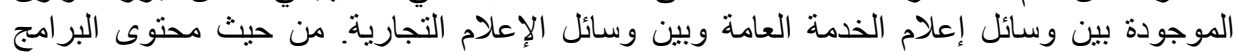

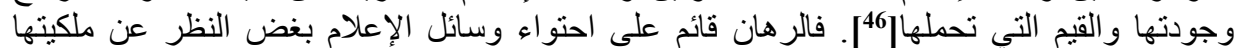

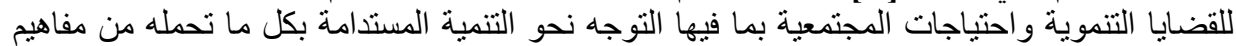

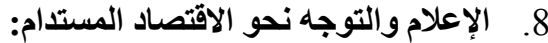

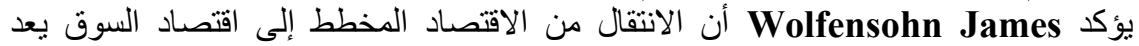

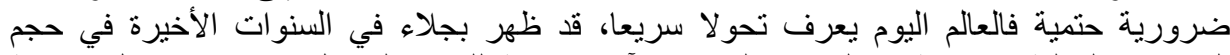

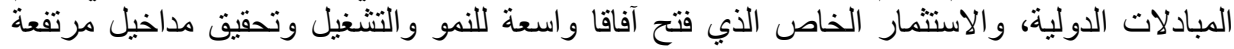

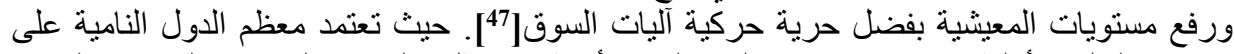

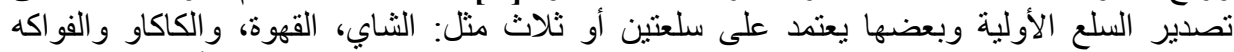

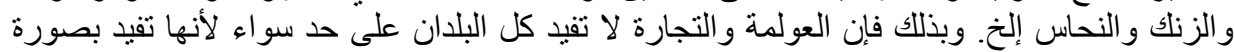

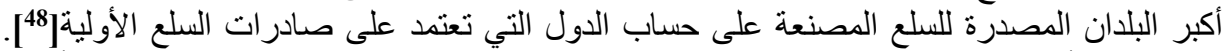

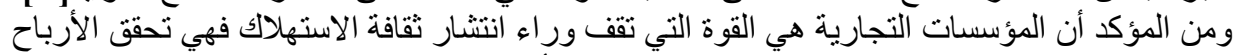

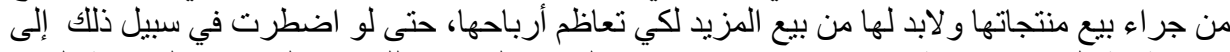
تغيير ثقافة الناس وبرمجة تفكير هم بما يتفق مع مصالحها. ولتحقيق ذللك تتبع الثركات التجارية التبارية العديد التيل

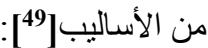
- بطاقة الائتمان و البيع بالتقسيط وهي طرق تسمح للمستهلكين بشر اء سلع تتجاوز قيمتها قدرتهم

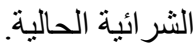

ـ تصميم المنتجات بحيث يكون عمر ها قصير ا، فإما أن تفنى سريعا، أو تصبح عتيقة الطراز بحيث يضطر المستهلك لاستبدالها حتى لو كانت ما تزال في حالة جيدة وتؤدي وظيفتها بشكل 
وطبعا فإن الوسيلة الأهم هي التسويق و الإعلان و الذي أصبح ميز انية ضخمة بلغ حجمها بليون

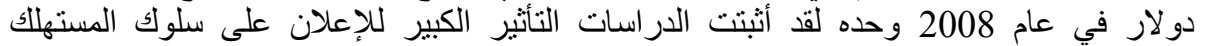

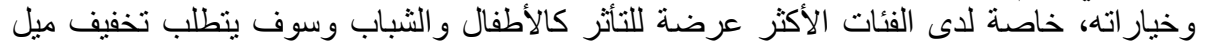

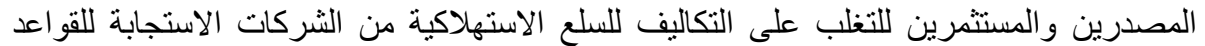

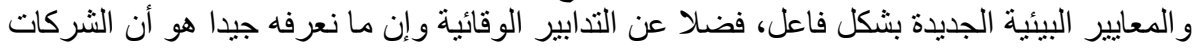

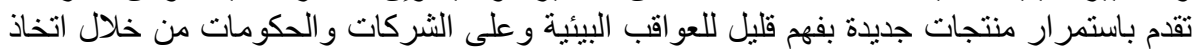

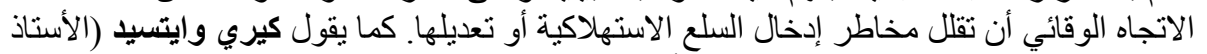

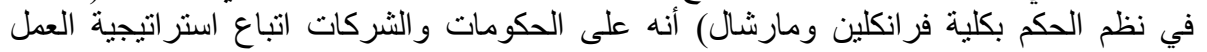

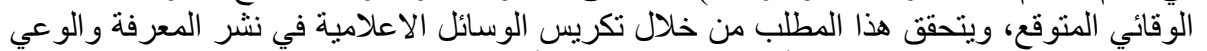

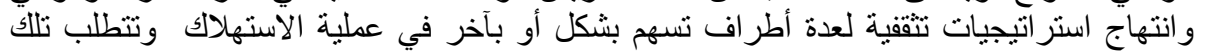

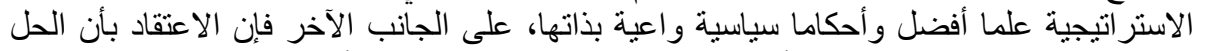

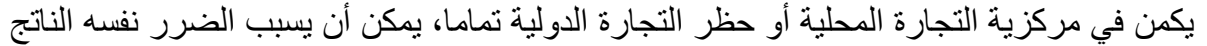

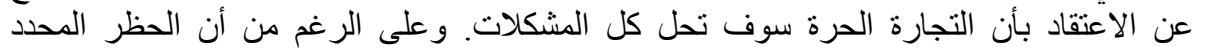

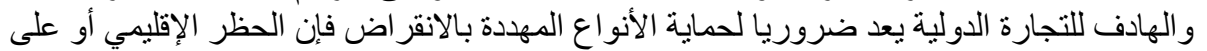

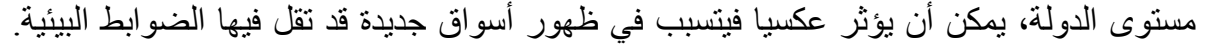
علاوة على ذلك يمكن لقيود التجارة أن تحمي المصانع التي لا تنتمتع بالكفاءة وأن تحفز الاستهلاك

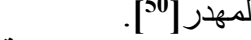

$$
\text { استختاجن }
$$

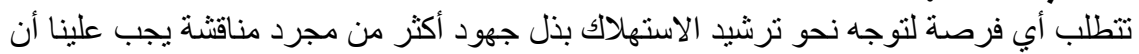

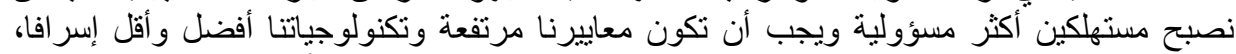

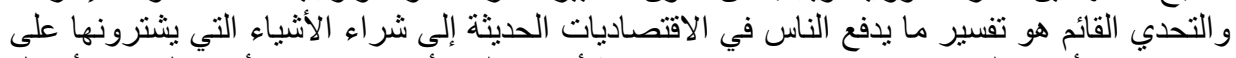

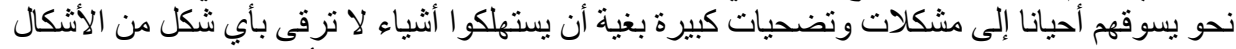

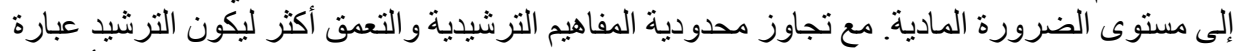

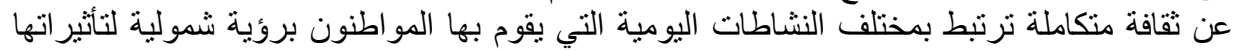

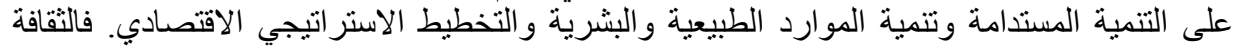

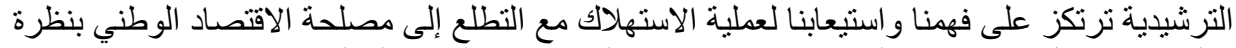

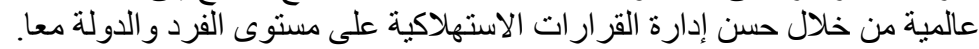

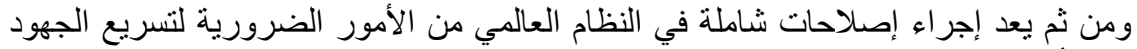

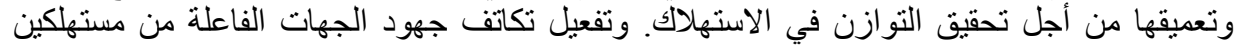
وجهات حكومية و غير حكومية و الإعلام الذي يعد حلقة وصل ودئ ودم للجهود المبذولة.

المراجع

[1] نصر الدين لعياضي، وسائل الإعلام واستراتجيات البناء الاجتماعي للأزمات، مجلة الحكمة

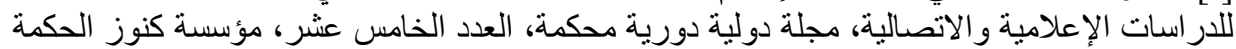

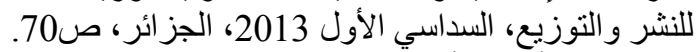
[2] [نظور أحمد الأزهري، ترشيد الاستهلاك الفردي في الاقتصاد الاسلامي، دار السلام للطباعة

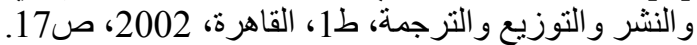

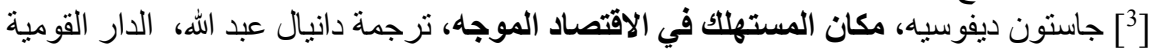

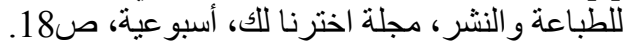

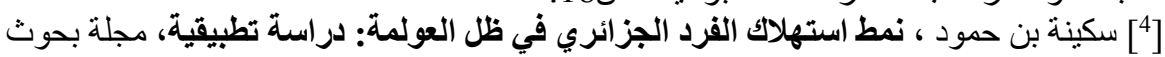

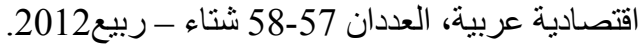


httpwww.univalger3.dzlabolabo_mondialisationtelechargementarticlesarticle_8 .pdf

[ [5] جون بودريار، مجتمع الاستهلاك، دراسة في أساطير النظام الاستهلاكي وتر اكيبه، تعريب خليل

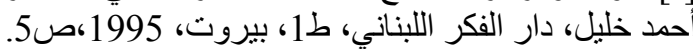
[ $\left.{ }^{6}\right]$ oxford University Press, oxford School Dictionnary,2011, "rationalism $"$

$$
\begin{aligned}
& \text { [7] [أنتوني غدنز، علم الاجتماع، ترجمة فايز الصياغ، المنظمة العربية للترجمة ومؤسسة ترجمان، }
\end{aligned}
$$

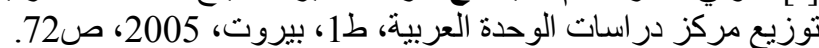

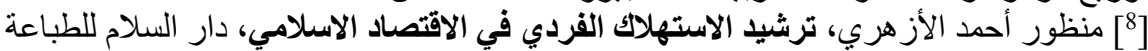

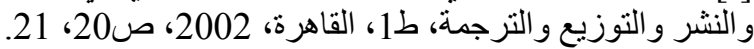

$$
\begin{aligned}
& \text { [9] المرجع نفساه، ص21. }
\end{aligned}
$$

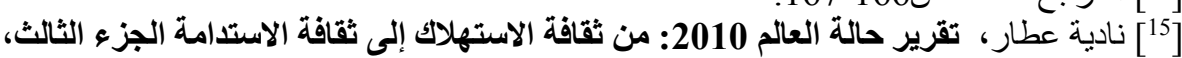
26 مارس 2012 نادئ 2015 permaculture research institute 17 2016/10/https://permaculturearabia.org .

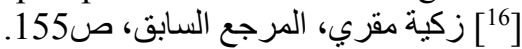

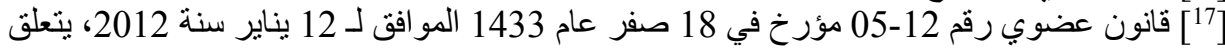

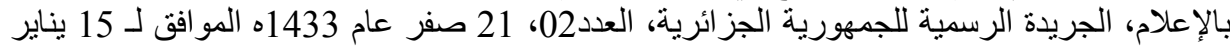

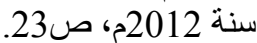

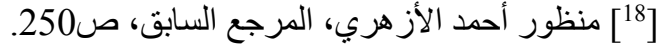

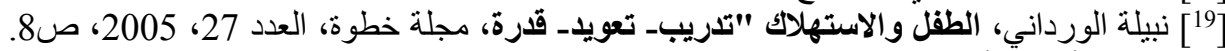

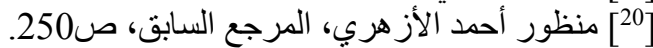

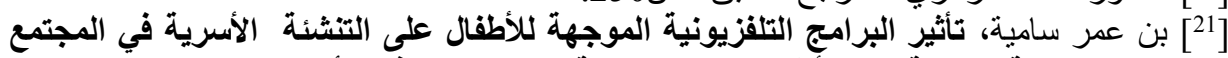

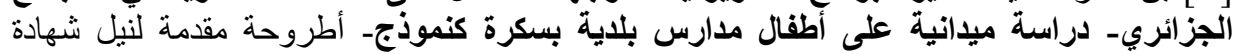

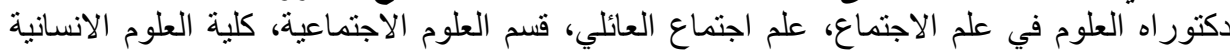

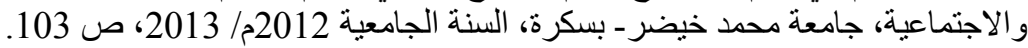

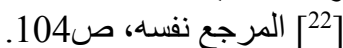
[23] روجر الررجع رونبلات، ثقافة الاستهلاك والحضارة والسعي وراء السعادة، ترجمة ليلى عبد الرزاق،

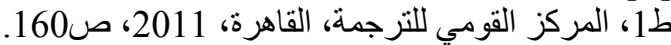

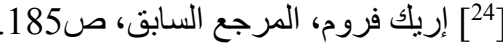
[الم

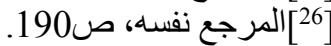
[27] باسكال بروكنز ، بؤس الرفاهيةـ ديانة السوق وأعداؤها، ترجمة عبد الله السيد ولد أباه، العابيكان،

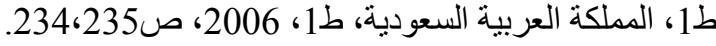




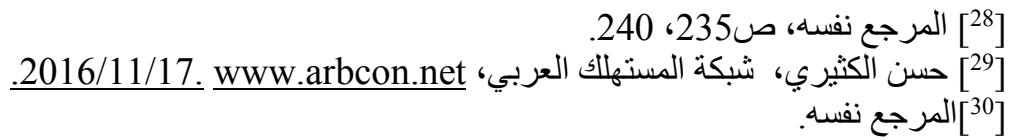

$\left.{ }^{[31}\right]$ Hicham Abdulabass Mohammed, The Relationship between the Requirements of Consumer Protection and Criteria Efficiency of Food and Thier Influence on Caseof Food Poisoning- Analysis Study for Opinions from Workers in Private Iraqi Health Sector, the Council of St Clements Univerrsity As Apart of Requirement of the Ph.D Degree in Health Administration, Bagdad, 2013, p34.

$\left.{ }^{[32}\right]$ ibid, p42.

$$
\text { [33] تصريح نائب الأمين العام لجمعية حماية المستهلك للر ائد في } 15 \text { ماي } 2015
$$

http://elraaed.com/ara/watan

$\left[{ }^{34}\right]$ Consumer Education, European Comission, Factsheet, December 2006, p 1 [35] بيتر دوفيرن، ظلال الاستهلاك (عواقب البيئة العالمية)، ترجمة مروى هانثم، هيئة أبو ظبي

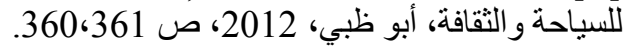

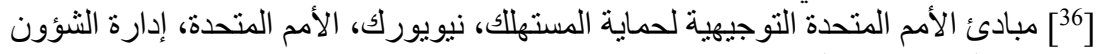

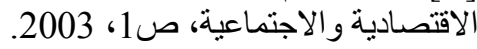
[35] مجلة الإذاعات العربية، مجلة فصلية تصدر عن اتحاد إذاعات الدول العربية، العدد1، 2013، ص 35

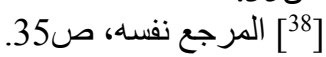

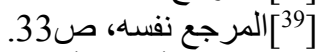

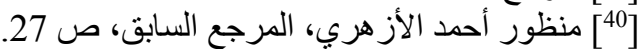

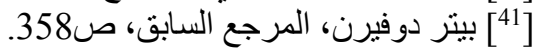

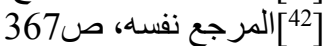

[43] محمد عمر حبيل، المظاهر الاجتماعية والثقافية المحددة لنمط الاستهلاك في المجتمع الليبي،

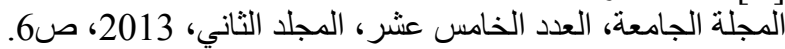

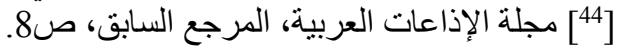

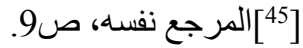

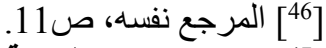

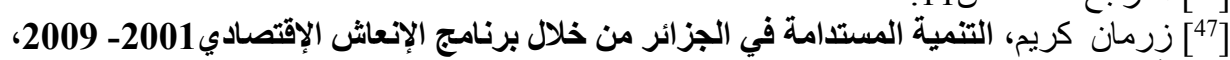

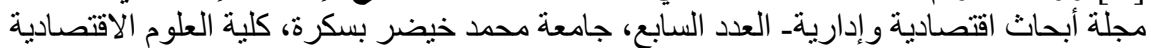

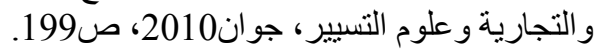

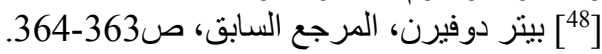

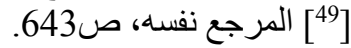

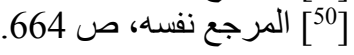

